\title{
Efficacy of neem (Azadirachta indica A. Juss) callus and cells suspension extracts against three lepidopteron insects of cotton
}

\author{
Muhammad Rafiq ${ }^{\star}$, M. Umar Dahot, S. Habib Naqvi, Mahadev Mali and Nadir Ali \\ Institute of Biotechnology and Genetic Engineering, University of Sindh, Jamshoro, Pakistan.
}

Accepted 7 June, 2012

\begin{abstract}
The efficacy of various preparations of neem (Azadirachta indica A. Juss) (NCE1) and cells suspension extracts (NCE2) was evaluated against three cotton insects including pink bollworm (Pectinophora gossypiella), bollworm (Helicoverpa armigera) and leafworm (Spodoptera litura). The cotton leaves and medium size excised bolls were sprayed with different dilutions of NCE1 and NCE2 and 3rd instar larvae were incubated. The dilutions T1 (1:10 v/v Extract: D. $\left.\mathrm{H}_{2} \mathrm{O}\right)$ and T2 $\left(1: 100 \mathrm{v} / \mathrm{v}\right.$ Extract: $\left.\mathrm{D} . \mathrm{H}_{2} \mathrm{O}\right)$ of both NCE1 and NCE2 showed highly significant results as almost $100 \%$ mortality was recorded after 2 to 3 days hours of larvae incubation. The larvae showed a repellent behavior, decrease in weight, and negligible leaf area damage. The preparation T3 (1:1000 v/v Extract: D. $\mathrm{H}_{2} \mathrm{O}$ ) showed 76 to $84 \%$ mortality, T4 (1:10000 v/v Extract: D. $\left.\mathrm{H}_{2} \mathrm{O}\right) 28$ to $72 \%$, and T5 (1:10000 v/v Extract: D. $\left.\mathrm{H}_{2} \mathrm{O}\right) 12$ to $40 \%$ mortality after the 5th day of incubation. The larvae also showed repellent to non repellent behavior, slow to moderate feeding activity with gradual increase of leaf area damage as extract preparations were diluted from T1 to T3. The control showed 96 to $100 \%$ survival of all the three insect species with active feeding activity, increase in insect weight and more than $50 \%$ leaf area damage after 2 nd day of incubation. In conclusion, the extracts of callus and cell suspensions of neem have insecticidal potential that showed significant mortality response against three bioassayed insects.
\end{abstract}

Key words: Mortality, neem callus, cells, cotton, incubation, insects.

\section{INTRODUCTION}

Neem tree (Azadirachta indica A. Juss) is an important source of secondary metabolites in nature and over 300 bioactive secondary compounds have been isolated including limonoids, phenolics, carotenoids, steroids, ketones, and enzymes (Kumar et al., 1996; Morgan and Wilson, 1999). Limonoids (tetranotriterpenoids) are the major group of secondary compounds such as azadirachtin, nimbin, nimbidin, salannin, etc (Jones et al., 1989; Govidachari et al., 1995). Due to its broad spectrum properties, low persistence in nature, low toxicity against non target organisms and systemic

${ }^{\star}$ Corresponding author. E. mail: rafijavid@hotmail.com or m.rafiq@usindh.edu.pk. Tel: +92-22-2772481 or +92-3003025250 . action, azadirachtin has received more attention as biopesticide and showed a great potential against insects (Immaraju, 1998; Prakash et al., 2002). Azadirachtin showed antifeedant effects on insects; the order Lepidoptera was found to be the most susceptible to azadirachtin as compared to other orders like Coleoptera, Hemiptera, and Homoptera (Ascher, 1993; Mordue and Blackwell, 1993). Azadirachtin may influence the insect's hormonal system and modifies the metamorphosis program. It seems to act as "ecdysone blocker" that blocks the release of vital hormones thus inhibiting insect's molting and causing disturbance of the life cycle and insect's production (Schmutterer, 1990; Ascher, 1993).

All neem-based commercial formulations used nowadays contain azadirachtin extracted from seeds of naturally grown neem plants. Collection of seeds is a 
labour intensive and expensive process. These seedsbased insecticides contain either low or variable concentrations of azadirachtin and other related triterpenoids because of different reasons like geographical distribution (Yakkundi et al., 1995), seasonal variation (Sidhu and Behl, 1996) and sensitivity of these compounds to environmental influences like temperature and light (Szeto and Wan, 1996; Jarvis, 1998). With the passage of time, the demand of azadirachtin based biopesticides is increasing (Immaraju, 1998) but only seed extracts of neem cannot meet the increasing demand of azadirachtin compound. Therefore, the development of commercially viable alternative sources like plant callus and cell suspension culture technique for azadirachtin production is urgently needed (Prakash et al., 2002). Biotechnological applications of plant cell culture technology provides a potential and valuable source of various medicinal compounds like flavors, fragrances and colorants which could not be produced through chemical synthesis or microbial cells. The antifeedancy of in vitro cultures of neem have been studied against desert locust (Kearney et al., 1994). The leaf callus extracts of neem have also shown larvicidal activity against Anopheles mosquito (Khalafalla et al., 2007). Keeping in view various applications of azadirachtin related limonoids, in the present study, the biotoxicity of neem callus and cells suspension extracts was evaluated against cotton bollworm (Helicoverpa armigera), pink bollworm (Pectinophora gossypiella), and leafworm (Spodoptera litura).

\section{MATERIALS AND METHODS}

The callus cultures were raised from immature flowers of neem on previously optimized media (Rafiq and Dahot, 2010) by first inoculating sterilized immature flowers of neem on Murashige and Skoog (MS) medium (Murashige and Skoog, 1962) supplemented with $1 \mathrm{mg} / \mathrm{L}$ 2,4-D, $1 \mathrm{mg} / \mathrm{L}$ BAP, $0.2 \mathrm{mg} / \mathrm{L}$ NAA and $9 \%$ sucrose solidified with $0.3 \%$ phytagel for 15 days and then subcultured on MS medium containing same concentrations of plant growth regulators and $3 \%$ sucrose in the growth room at $25 \pm 2^{\circ} \mathrm{C}$ in $14 \mathrm{~h} / 10$ $h$ light/dark photoperiod and 2000 lux light intensity. The proliferating calli were subcultured on the same medium after every 15 days interval. For establishment of cells suspension cultures, $5 \mathrm{~g}$ of proliferating callus was first crushed and then inoculated in MS liquid medium supplemented with $1 \mathrm{mg} / \mathrm{L}$ 2,4-D, $1 \mathrm{mg} / \mathrm{L}$ BAP, 0.2 $\mathrm{mg} / \mathrm{L} \mathrm{NAA}$ and $3 \%$ sucrose and was incubated at $25 \pm 2{ }^{\circ} \mathrm{C}$ on shaking incubator at $90 \mathrm{rpm}$ and in $14 \mathrm{~h} / 10 \mathrm{~h}$ light/dark photoperiod and 2000 lux light intensity. The suspension cells were subcultured for six times in same fresh liquid medium after every seven days interval to get homogenized suspension cells.

For preparation of azadirachtin-based extracts, callus and cell suspension were dried at $40^{\circ} \mathrm{C}$ on filter papers separately for $72 \mathrm{~h}$. For extraction, $20 \mathrm{~g}$ samples were ground with a pestle and mortar in $10 \mathrm{ml}$ methanol. The extracts were centrifuged at $8000 \mathrm{rpm}$ and $4^{\circ} \mathrm{C}$, the supernatant was collected and subjected to extraction twice. The methanol was evaporated in $40^{\circ} \mathrm{C}$ water bath and the remaining crude material was resuspended in $20 \mathrm{ml}$ of distilled water $\left(\mathrm{D} . \mathrm{H}_{2} \mathrm{O}\right)$. The azadirachtin related limonoids were quantified following Dai et al. (1999) method. For this purpose $0.7 \mathrm{ml}$ of test sample was taken in a test tube and $0.2 \mathrm{ml}$ of methanol containing vanillin solution $(0.02 \mathrm{mg}$ of vanillin in $1 \mathrm{ml}$ of methanol) was added. The reaction mixture was manually shaken for $2 \mathrm{~min}$ at room temperature; $0.3 \mathrm{ml}$ of concentrated $\mathrm{H}_{2} \mathrm{SO}_{4}$ was carefully added in test tube and was stirred for few seconds, which developed twolayered mixture. Finally, $0.7 \mathrm{ml}$ of methanol was added in test tube that developed blue green colour. The reaction mixture was placed at room temperature for $5 \mathrm{~min}$ and the absorbance was measured at $577 \mathrm{~nm}$ on UV-visible spectrophotometer. The azadirachtin related limonoids were calculated from standard graph of Azadirachtin, and finally, it adjusted the extracts to $1 \mathrm{mg} / \mathrm{ml}$. For laboratory scale insect feeding bioassays, both neem callus extracts (NCE1) and neem cells suspension extracts (NCE2) were diluted with $\mathrm{D} . \mathrm{H}_{2} \mathrm{O}$ separately with the following ratios: T1: $(1: 10$ v/v) Extract: D. $\mathrm{H}_{2} \mathrm{O}$; T2: (1:100 v/v) Extract: D. $\mathrm{H}_{2} \mathrm{O}$; T3: $(1: 1000 \mathrm{v} / \mathrm{v})$ Extract: D. $\mathrm{H}_{2} \mathrm{O}$; T4: (1:10000 v/v) Extract: D. $\mathrm{H}_{2} \mathrm{O}$; T5: $(1: 100000$ v/v) Extract: D. $\mathrm{H}_{2} \mathrm{O}$; C: (Control) only D. $\mathrm{H}_{2} \mathrm{O}$.

The efficacy of different dilutions of NCE1 and NCE2 was evaluated in insect bioassays against three chewing insects of cotton including pink bollworm ( $P$. gossypiella), cotton bollworm $(H$. armigera), and cotton leafworm ( $S$. litura). The insects (caterpillars) were collected during August to October, 2010 from a cotton field at Tandojam, Sindh Pakistan.

For laboratory bioassay, medium size $\left(3 \mathrm{~cm}^{2}\right)$ fresh leaves and small bolls ( 1.2 to $1.5 \mathrm{~cm}$ diameter size) were collected from cotton field, washed with distilled water and blotted dry with tissue paper. The leaves were either cut into two pieces containing midrib or used in full. They were sprayed with different dilutions (T1, T2, T3, T4, and T5) of extracts (NCE1 and NCE2) and then placed in Petri dishes. For negative control, leaves were sprayed with distilled water. Three third instar larvae of cotton leafworm collected from Nuclear Institute of Agriculture (NIA), Tandojam, Pakistan were used per Petri dishes in triplicates and the experiment was repeated four times, thus a total of 36 insects were used for each treatment. For pink worm and cotton bollworm, small sized bolls were either cut from center or used in full. They were sprayed with different dilutions of each extract and the control was sprayed with distilled water and was placed in Petri dishes. The bioassay plates were incubated at $30 \pm 2{ }^{\circ} \mathrm{C}$ with 80 to $90 \%$ humidity in low light intensity of 500 lux and the data was recorded every $24 \mathrm{~h}$ for 5 days. The mortality rate was calculated by determining the percentage of dead insects based on the following formula:

$$
\text { Mortality }(\%)=\frac{\text { Number of insects dead/experiment }}{\text { Total number of insects/experiment }} \times 100
$$

The insects repellent and post feeding behavior and damaged leaf area were recorded. The experiments were conducted in three replicates and mean values were taken. The data was statistically evaluated to determine variance and standard error (SE) of the mean.

\section{RESULTS}

Laboratory scale bioassay was conducted against cotton bollworm $(H$. armigera), pink bollworm ( $P$. gossypiella) and cotton leafworm ( $S$. litura) using crude extracts of neem callus and suspension cells. According to results, preparations T1 and T2 of both NCE1 and NCE2 extracts showed $100 \%$ mortality after 3 to 4 days of incubation. Among all the preparation, T1 of both NCB1 and NCB2 extracts showed the highly significant results with 18 to $52 \%$ larval death after 1 day and $100 \%$ mortality of all three bioassayed insect species after 2 to 3 days of 
NCE1

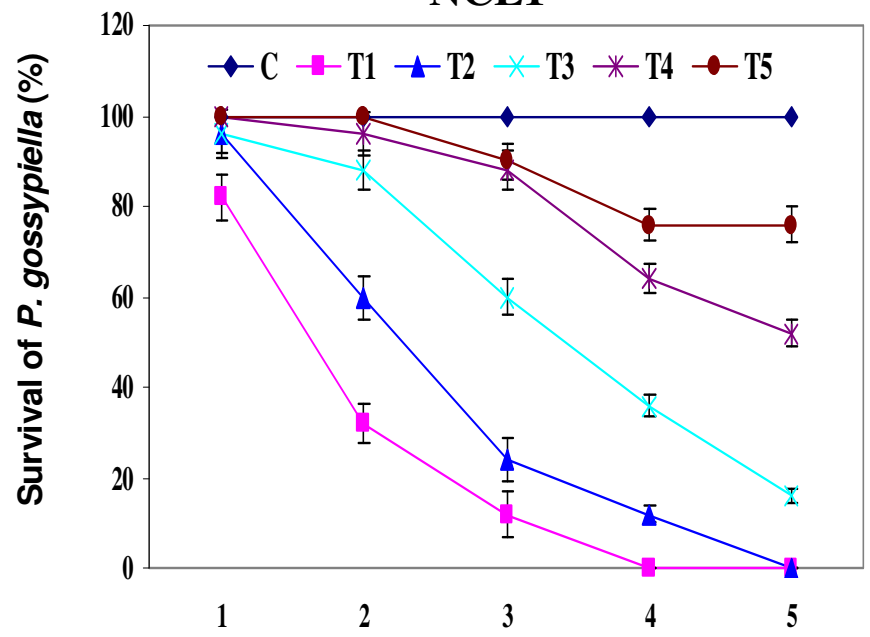

Time period (day)
NCE2

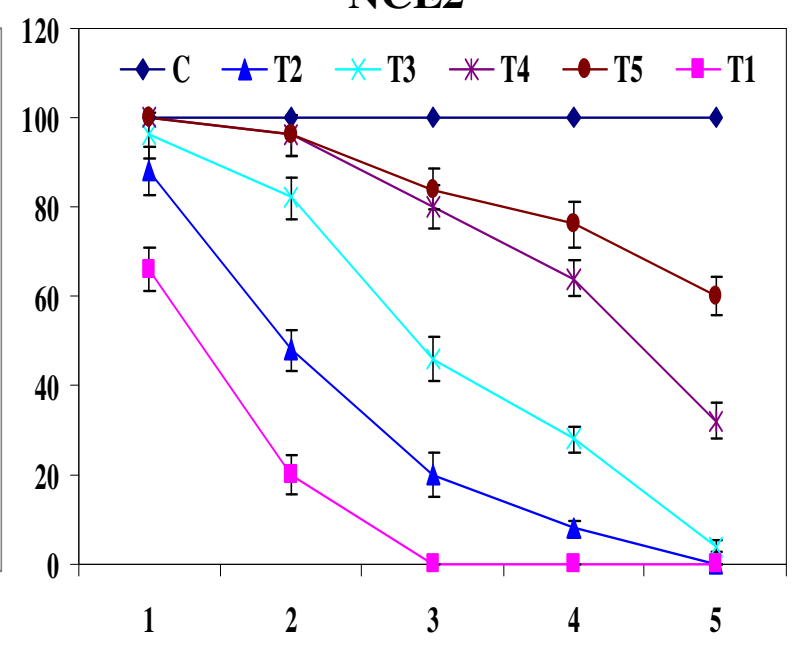

Time period (day)

Figure 1. Effect of various concentrations of NCE1 and NCE2 on mortality of pink bollworm (P. gossypiella) (Mean \pm S.E).
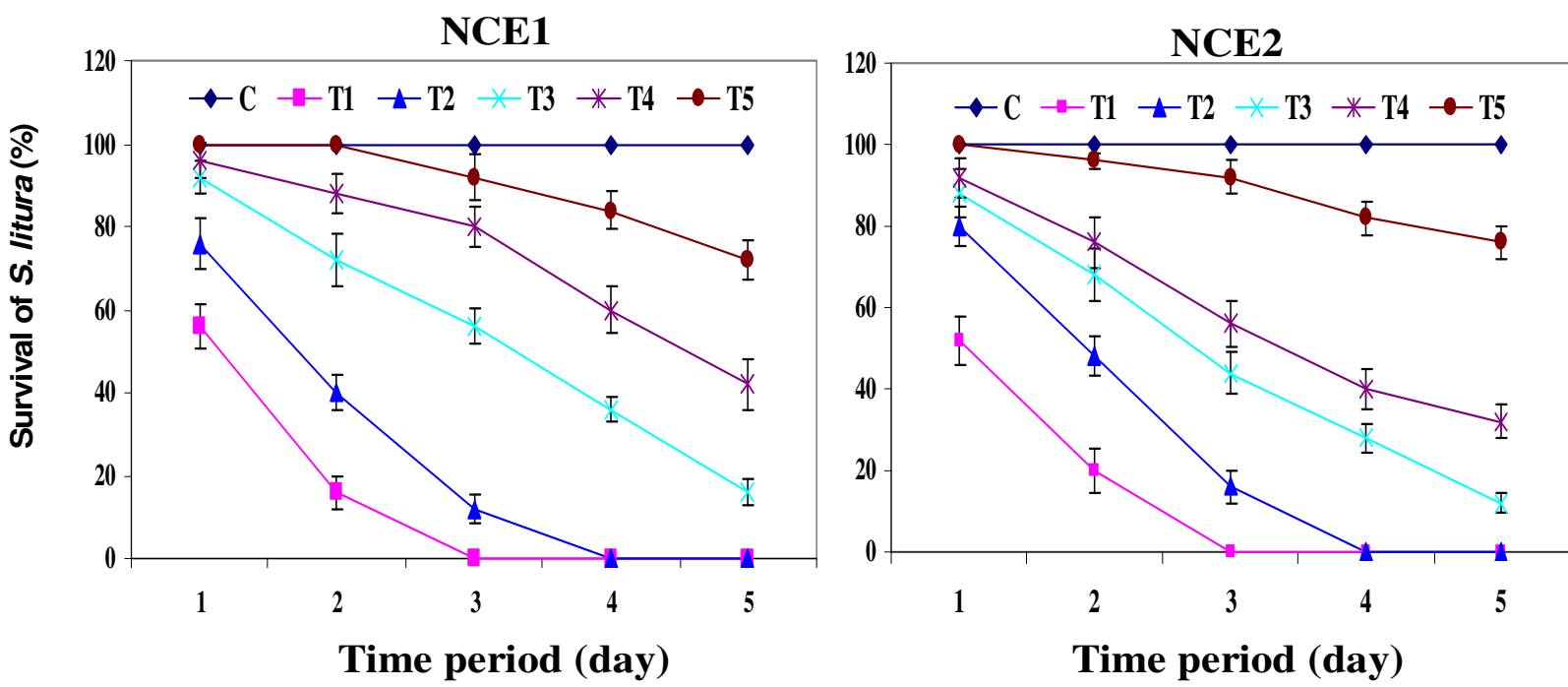

Time period (day)

Figure 2. Effect of various concentrations of NCE1 and NCE2 on mortality of cotton leafworm (S. litura) (Mean \pm S.E).

incubation (Figures 1, 2, and 3). The preparation T1 (1:10 $\mathrm{v} / \mathrm{v}$ Extract: $\mathrm{D} . \mathrm{H}_{2} \mathrm{O}$ ) showed the highest biotoxicity response against cotton leafworm as all larvae were dead during 1 to 2 days (Figure 3), followed by $100 \%$ morality against cotton pink bollworm after 2 to 3 days (Figure1), while against cotton bollworm after 4 to 5 days (Figure 3 ), respectively as compared to the control where $100 \%$ survival of cotton leafworm and cotton pink bollworm was observed, while $96 \%$ survival of cotton bollworm was observed. The larvae also showed decreased weight and repellent behavior as compared to control where significant increase in weight was observed (Figure 4A,
B, and C). Similarly, cotton leafworms showed negligible chewing activity with almost negligible leaf area damage in $\mathrm{T} 1$ preparations as compared to the control where above $50 \%$ leaf area damage was recorded after 2 days of incubation (Figure 4D, E, and F).

When T2 (1:100 v/v Extract: D. $\left.\mathrm{H}_{2} \mathrm{O}\right)$ preparations of both NCB1 and NCB2 were applied against all three insects species, $100 \%$ morality was observed against cotton leafworm within 2 to 3 days and against cotton pink bollworm within 5 days, while cotton bollworm showed 96 to $100 \%$ mortality after 5 days of incubation. The larvae also showed repellent behavior, decrease in 

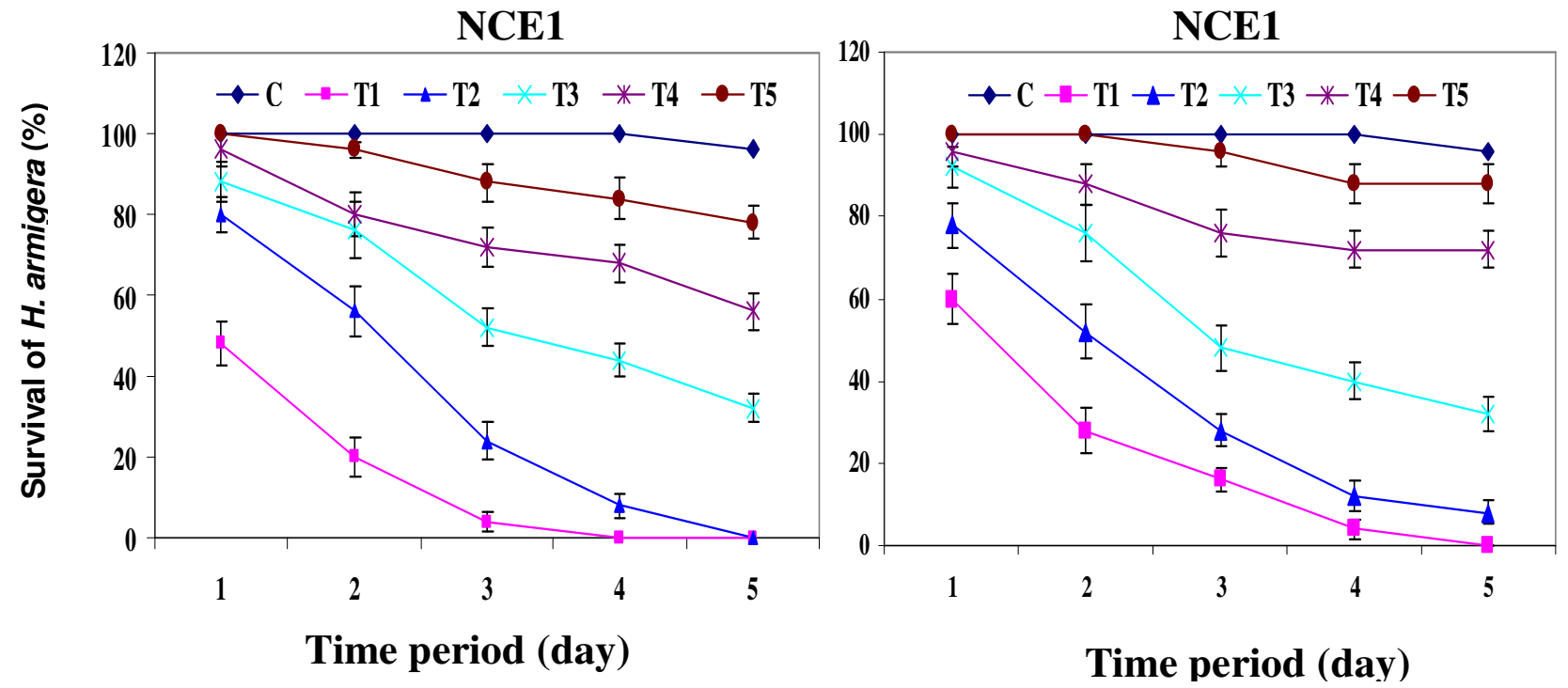

Figure 3. Effect of various concentrations of NCE1 and NCE2 on mortality of cotton bollworm (H. armigera) (Mean \pm S.E).

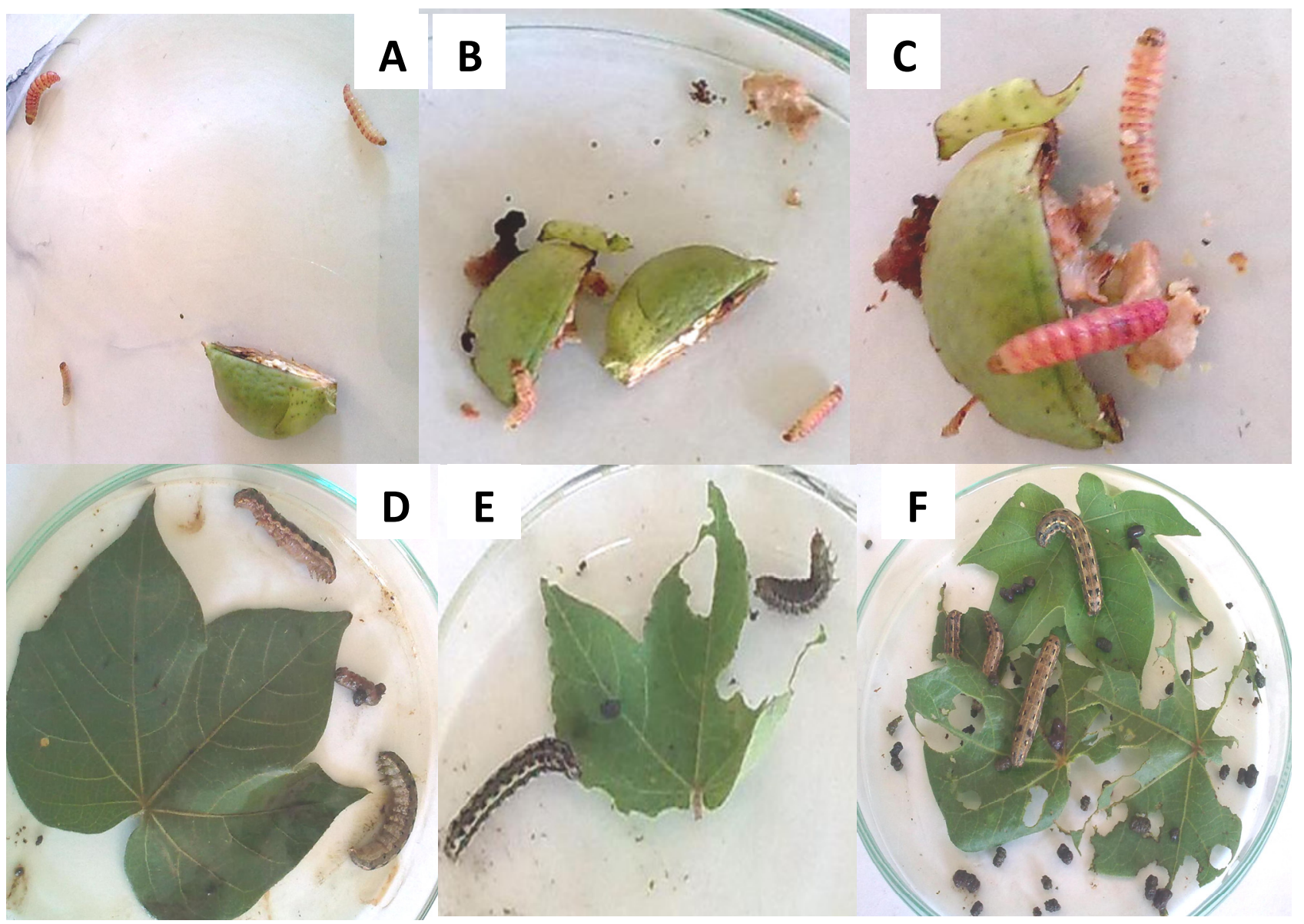

Figure 4. Insect feeding bioassay against pink bollworm and cotton leaf worm. A and B: Treated bolls with T1 showing repellent effect of insects with dead and alive pink bollworm with no increase in weight after 2 days of treatment; C: Negative control showing all alive pink bollworm with increase in weight after 3 days of treatment; D: Leaves sprayed with T1 dilution showing all dead leafworms after 24 h; E: Leaves sprayed with T3 dilution showing slow feeding after 2 days; F: Negative Control showing active feeding activity of leafworms after 2 days. 
weight and negligible leaf area damage. The preparations T3 (1:1000 v/v Extract: D. $\left.\mathrm{H}_{2} \mathrm{O}\right)$ of NCE1 and NCE2 extracts also showed good mortality response (76 to $84 \%$ ) after 5th day of incubation. Here, larvae showed slow feeding behavior with about $20 \%$ damaged leaf area recorded. As T4 preparations $(1: 10000 \mathrm{v} / \mathrm{v}$ Extract: D. $\mathrm{H}_{2} \mathrm{O}$ ) were sprayed, 56 to $60 \%$ mortality was recorded in cotton leafworm (Figure 2), 56 to $64 \%$ in pink bollworm and 24 to $40 \%$ in cotton bollworm, respectively on 5th day of incubation of larvae. The least mortality was recorded in T5 preparations $(1: 100000 \mathrm{v} / \mathrm{v}$ Extract: D. $\mathrm{H}_{2} \mathrm{O}$ ) as only 12 to $40 \%$ mortality was recorded and 60 to $88 \%$ insects were found alive with moderate feeding behavior after 5th day of incubation (Figures 1, 2, and 3). Similarly, insects showed no repellent behavior and moderate feeding with about 45 to $50 \%$ leaf area damage.

\section{DISCUSSION}

The bioactivity of neem extracts against insects has also been reported. Azadirachtin has been reported to control different insects of orders Lepidoptera, Coleoptera, Hemiptera, and Homoptera including armyworms, pink bollworms, leaf worms, caterpillars, beetles, mushroom flies, gypsy moths, etc. (Ascher, 1993; Mordue and Blackwell, 1993). Azadirachtin may limit the feeding of many insects that may lead to insect death (Thomson, 1992) or may influence the hormonal system, especially ecdysone that modifies the metamorphosis program of insects (Schmutterer, 1990). In the present study, 3rd instar larvae of pink bollworms, leaf worms and cotton bollworm were used in bioassays. A highly significant mortality response (100\% mortality) was recorded from $\mathrm{T} 1$ and T2 preparations of both NCE1 and NCE2 extracts. Most of the larvae were in 3rd stage to caterpillar's stage, which may be more resistant to neem callus and cells extracts as compared to 1st and 2nd stage larvae; however, an encouraging mortality response (85 to 100\%) was observed in T1, T2, and T3 preparations of both NCE1 and NCE2 extracts. As the preparations were further diluted (T4 and T5), mortality rate was decreased and number of surviving insects was increased, this may be due to dose quantity or time of application of insects. These results are in agreement with previous reports. The effect of azadirachtin depend on both dosage and time of application that prevent ecdysis and apolysis, which leads to death before or during molting stage and probably induce larvae permanently (Mordue and Blackwell, 1993).

Ascher (1993) comparatively assessed antifeedant and toxic properties between azadirachtin and biosynthetic precursors against larvae of Spodoptera littoralis (Boisd), Schistocerca gregaria and Oncopeltus fasciatus Dallas. Among three bioassayed species, $P$. gossypiella and Spodoptera litura found more sensitive NCE1 and NCE2 extracts than $H$. armigera. Both species ( $P$. gossypiella and $S$. litura) showed higher mortality rate, less feeding and higher insect repellent behavior. The biotoxicity to insects from severe growth reduction and moult disruption was observed in azadirachtin related limonoids and the insect growth regulatory effects of azadirachtin related limonoids were found amazingly alike between species. Other researchers also reported the efficacy of neem extracts against insects. Huang et al. (2004) found changes in proteins metabolism induced due to azadirachtin in $S$. litura, a protein may regulate development and reproduction of insect as an ecdysone receptor and it may be suggested that azadirachtin based insecticides affects expression of these protein expression. Deota and Upadhyay (2005) also assessed synthetic transformations of azadirachtin-A against 2nd instars larvae of $S$. litura and found azadirachtin as high crop protection in combination of insect toxicity and antifeedancy. Similarly, Greenberg et al. (2005) found that neem-based insecticides deterred feeding by beet armyworm larvae. Jotwani and Srivastava (1984) reported that larvae of Chilo partellus treated with neem seed extract either died during the process of development or the adults emerging from the surviving larvae were abnormal. Kearney et al. (1994) also studied the antifeedancy of callus and suspension cells extracts against desert locust.

\section{Conclusion}

In most of the previous reports, extracts of different parts of intact plants like leaf, bark, flower and fruit were used for antifeedent and bioassays study, but in present study, neem callus and cells suspension extracts were used in bioassays that showed significant mortality response against 3rd instar larvae of cotton $P$. gossypiella, $S$. litura and $H$. armigera. The surviving insects showed the behavior with decrease in insect weight and slower feeding activity as compared to the controls. The efficacy of these extracts may be further enhanced by using 1st and 2nd instar larvae of these insects in bioassays as well as optimizing dose concentration and treatment time.

\section{REFERENCES}

Ascher KRS (1993). Nonconventional insecticidal effects of pesticides available from the Neem tree, Azadirachta indica. Arch. Insect Biochem. Physiol. 22:433-449.

Dai J, Yaylayan VA, Raghavan GSV, Pare JR (1999). Extraction and colorimetric determination of azadirachtin-related limonoids in neem seed kernel. J. Agric. Food Chem. 47:3738-3742.

Deota PT, Upadhyay PR (2005). Biological studies of azadirachtin and its derivatives against polyphagous pest, Spodoptera litura. Nat. Prod. Res. 19:529-539.

Govidachari TR, Narasimhan NS, Suresh G, Partho PD, Gopalakrishnan G, Kumari GNK (1995). Structure related insect antifeedant and growth regulating activities of some liminoids. $\mathrm{J}$. Chem. Enol. 21:1585-1600.

Greenberg SM, Showler AT, Liu TX (2005). Effects of neem-based insecticides on beet armyworm (Lepidoptera: Noctuidae). Insect Sci. 12:17-23. 
Huang Z, Shi P, Dai J, Du J (2004). Protein metabolism in Spodoptera litura (F.) is influenced by the botanical insecticide azadirachtin. Pestic. Biochem. Physiol. 80:85-93.

Immaraju JA (1998). The commercial use of azadirachtin and its integration into viable pest control programmes. Pestic. Sci. 54:285289.

Jarvis AP (1998). Isolation and degradation of triterpenoids from tissue cultures and seeds of neem (Azadirachta indica), PhD dissertation, University of Keele, Keele, UK.

Jones PS, Ley SV, Morgan ED, Santafianos D (1989). The chemistry of the neem tree, In; Jacobson (eds). Focus on Phytochemical Pesticides, The Neem Tree, CRC Press, Boca Raton, Florida 1:1945.

Jotwani MG, Srivastava KP (1984). A review of neem research in India in relation to insects. In: Proceedings of International Neem Conference, Ranicholzhausen, Germany pp. 43-56.

Kearney ML, Allan EJ, Hooker JE, Mordue AJ (1994). Antifeedant effects of in vitro culture extracts of the neem tree (Azadirachta indica) against the desert locust (Schistocerca gregaria Forkskal). Plant Cell Tiss. Org. Cult. 37:67-71.

Khalafalla MM, El Gaali El, Abbas FM, Ali HA (2007). Neem callus induction and its larvaecidal activity against Anopheles mosquito. Int. J. Biotech. Biochem. 3:1-8.

Kumar CSSR, Srinivas M, Yakkundi S (1996). Limonoids from the seeds of Azadirachtin indica. Phytochemistry 43:451-455.

Mordue AJ, Blackwell A (1993). Azadirachtin: an update. J. Insect Physiol. 39:903-924.
Morgan ED, Wilson ID (1999). Insect hormones and insect chemical ecology. In: Mori $\mathrm{K}$ (eds) Comprehensive Natural Products Chemistry, Elsevier, Amsterdam 8:324.

Murashige T, Skoog F (1962). A revised medium for rapid growth and bioassays with tobacco tissue culture. Physiol. Plant 15:473-497.

Prakash G, Bhojwani SS, Srivastava AK (2002). Production of azadirachtin from plant tissue culture-state of the art and future prospects, Biotechnol. Bioprocess Eng. 7:185-193.

Rafiq M, Dahot MU (2010). Callus and azadirachtin related limonoids production through in vitro culture of neem (Azadirachta indica A. Juss) Afr. J. Biotechnol. 9:449-453.

Schmutterer H (1990). Properties and potential of natural pesticides from the neem tree, Azadirachta indica. Annu. Rev. Entomol. 35:271297.

Sidhu OP, Behl MH (1996). Seasonal variations in azadirachtin in seeds of Azadirachta indica. Curr. Sci. 70:1084-1086.

Szeto SY, Wan MT (1996). Hydrolysis of azadirachtin in buffered and natural water. J. Agric. Food Chem. 44:1160-1163.

Thomson WT (1992). Agricultural Chemicals: Book In: Insecticides, Thomson Publications, Fresno, CA.

Yakkundi SR, Thejavathi R, Ravindranath B (1995). Variation of azadirachtin content during growth and storage of neem (Azadirachta indica) seeds. J. Agric. Food Chem. 43:2517-2519. 